\title{
Experimental Study on Carbonization of Magnesium Slag Cement
}

\author{
Yuheng Dai ${ }^{1 *}$, Jianxun $\mathrm{Ma}^{1}$, Chen Guo ${ }^{1}$ and $\mathrm{Xin} \mathrm{Xu}^{1}$ \\ ${ }^{1}$ School of Human Settlements and Civil Engineering, Xi' an Jiaotong University, Xi' an, Shanxi Province, 710049, China
}

\begin{abstract}
Magnesium slag is a kind of industrial waste with the similar chemical composition to silicate cements, which is of hydration activity to some extent. However, the hydration activity of magnesium slag is much lower than that of traditional silicate cements. Through the method of carbonization, this experiment enhanced the hydration activity of magnesium slag, so that the strength of magnesium slag products can meet the requirements of structures together with certain mechanical and physical properties as well.
\end{abstract}

\section{Introduction}

Magnesium slag is a kind of industrial waste which has the potential to replace the traditional silicate cements. The elemental composition and crystal habit are the two biggest differences between magnesium slag and silicate cement clinker. The key ingredients of hydration reaction are $\beta-\mathrm{C} 2 \mathrm{~S}$, while the component crystal of elements $\mathrm{Si}, \mathrm{O}$ and $\mathrm{Ca}$ in magnesium slag is $\gamma$-C2S. Although they share the same type of elements, they are two completely different substances. The chemical activity of the latter is much lower than that of the former, which is the key factor that makes it difficult for magnesium slag to be directly used as a substitute for cement clinker, which is also the reason for conducting this study.

\section{Principle of gas carbonization}

The melting temperature of magnesium is $1200^{\circ} \mathrm{C}$, and the temperature of magnesium slag is $1200^{\circ} \mathrm{C}$ when it is just produced. At this point, the main ingredient of magnesium slag is $\beta-\mathrm{C} 2 \mathrm{~S}$. With temperature decreasing, the crystal comes to transform at $600^{\circ} \mathrm{C}$,during which $\beta$-C2S gradually transforms to $\gamma-\mathrm{C} 2 \mathrm{~S}$, leading magnesium slag merely loses all its hydraulicity. Therefore, the point of this experiment is to stimulate the activity of $\gamma$-C2S.

It has been studied that the hydration activity of $\gamma-\mathrm{C} 2 \mathrm{~S}$ manifests differences in different mediums. In mediums with different $\mathrm{pH}$ Value, the order of activity is:

$$
\mathrm{H}_{2} \mathrm{O}>\mathrm{NaOH} \text { (solution) }>
$$

$\mathrm{CaSO}_{4} \cdot 2 \mathrm{H}_{2} \mathrm{O}+\mathrm{H}_{2} \mathrm{O}>\mathrm{CaSO}_{4} \cdot 2 \mathrm{H}_{2} \mathrm{O}+\mathrm{NaOH}$ (solution)

Based on the above, the acid activation may be viewed as a possible experimental method. For $\mathrm{CO}_{2}$ is a common acid gas, and the main components of magnesium slag can theoretically react with $\mathrm{CO}_{2}$ to generate $\mathrm{CaCO}_{3}$ to improve material strength. At the same time, the $\mathrm{SiO}_{2}$ gel, which generated during the process of carbonization can strengthen material viscosity, so as to further enhance its strength

\section{Gas Carbonization experiment}

\subsection{Gas carbonization experiment on pure} magnesium slag under atmospheric pressure Pouring the mix of magnesium slag specimen and water into grinding apparatus, pressing and vibrating the specimen into shape, then the specimen was taken out in the $\mathrm{CO} 2$ gas for curing immediately after demoulding. After $\mathrm{CO} 2$ dissolving in the pores of magnesium slag, the water turned to be faintly acid. The research took hydration reaction specimen as the control group, and the water-cement ratio range was controlled between 0.25 to 0.325 to reach the best hydration effect. The test parameters are shown in Table 1:

Table 1.Ratio of magnesium slag carbonization

\begin{tabular}{|c|c|c|c|c|}
\hline Number & & $\begin{array}{c}\text { Water-cem } \\
\text { ent ratio }\end{array}$ & $\begin{array}{l}\text { Magnesium } \\
\text { slag/g }\end{array}$ & Water/g \\
\hline $3-1-1$ & $\begin{array}{l}\mathrm{a} \\
\mathrm{b} \\
\mathrm{c}\end{array}$ & 0.25 & 1300 & 325 \\
\hline $3-1-2$ & $\begin{array}{l}\mathrm{a} \\
\mathrm{b} \\
\mathrm{c}\end{array}$ & 0.275 & 1200 & 330 \\
\hline $3-1-3$ & $\begin{array}{l}\mathrm{a} \\
\mathrm{b} \\
\mathrm{c}\end{array}$ & 0.3 & 1200 & 360 \\
\hline $3-1-4$ & $\begin{array}{l}\mathrm{a} \\
\mathrm{b} \\
\mathrm{c}\end{array}$ & 0.325 & 1100 & 357.5 \\
\hline
\end{tabular}

Experimental results:

\footnotetext{
* Corresponding author:709861886@qq.com
} 
After the ordinary hydration reaction, it can be seen that most of these specimens have had certain mechanical strength, while some of them have broken during the process of demoulding due to their low strength. The specific data is shown in table 2:

Table 2.Results of magnesium slag carbonization experiment under atmospheric pressure

\begin{tabular}{cccccc}
\hline $\begin{array}{c}\text { Numb } \\
\text { er }\end{array}$ & \multicolumn{4}{c}{$\begin{array}{c}\text { Flexural } \\
\text { strength/MPa }\end{array}$} & \multicolumn{2}{c}{$\begin{array}{c}\text { Compressive } \\
\text { strength/MPa }\end{array}$} \\
\hline \multirow{3}{*}{$3-1-1$} & a & 2.7 & & 6.65 & \\
& $\mathrm{~b}$ & 2.2 & 2.45 & 6.4 & 6.47 \\
& $\mathrm{c}$ & - & & 6.35 & \\
\cline { 2 - 6 } $3-1-2$ & $\mathrm{a}$ & - & & 5.9 & \\
& $\mathrm{~b}$ & - & 2.2 & 5.8 & 5.82 \\
& $\mathrm{c}$ & - & & 5.75 & \\
\cline { 2 - 6 } $3-1-3$ & $\mathrm{a}$ & 1.8 & & 3.7 & \\
& $\mathrm{~b}$ & 2.3 & 2.07 & 4.25 & 3.98 \\
& $\mathrm{c}$ & 2.1 & & 4 & \\
\cline { 2 - 6 } $3-1-4$ & $\mathrm{a}$ & 1.7 & & - & \\
& $\mathrm{b}$ & 1.7 & 1.70 & - & - \\
\hline
\end{tabular}

In the experiment of compressive strength test, the experimental data of group 3-1-4 can not be read by instruments due to the low compressive strength of which. The above shows that the hydration reaction conducted by magnesium slag alone can hardly be carried out, or it is difficult for the hydration product to bring higher strength due to its low viscosity. This result indicates that the flexural strength of the magnesium slag specimen is higher, while the compressive strength is lower. Compared with the uncarbonized experimental group, the flexural strength of the specimen has increased to some extent, but the compressive strength has no significant change. The reason may be that the carbon dioxide could not penetrate into the interior of the specimen under atmospheric pressure, resulting in an insufficient carbonization.

\subsection{Gas carbonization experiment under pressurized atmosphere}

This experiment is similar with the former, the difference is that the gas pressure of this experiment was set between 0.2 to $0.3 \mathrm{MPa}$ by specialized carbonization furnace during the maintenance phase. The carbonization furnace is shown in Figure 1:

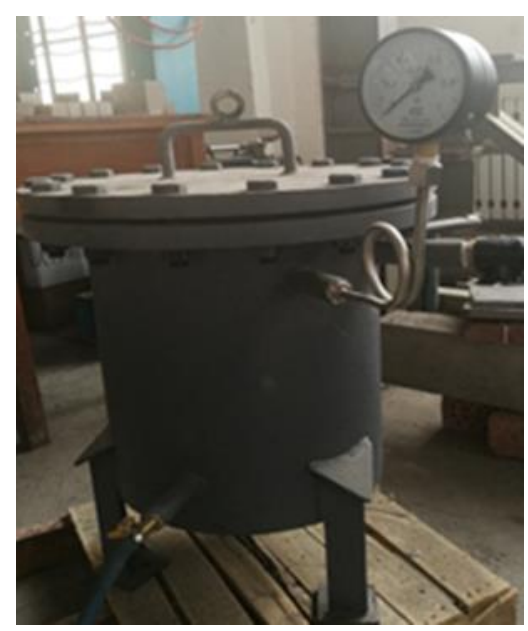

Figure 1. Carbonization furnace

Table 3. Ratio of gas carbonization under pressurized atmosphere

\begin{tabular}{cccc}
\hline Number & $\begin{array}{c}\text { Water-cement } \\
\text { ratio }\end{array}$ & $\begin{array}{c}\text { Magnesium } \\
\text { slag/g }\end{array}$ & Water/g \\
\hline $5-1-1$ & 0.275 & 1200 & 330 \\
$5-1-2$ & 0.3 & 1300 & 390 \\
$5-1-3$ & 0.325 & 1300 & 422.5 \\
\hline
\end{tabular}

Table 4. Results of gas carbonization experiment under pressurized atmosphere

\begin{tabular}{cccccc}
\hline $\begin{array}{c}\text { Num } \\
\text { ber }\end{array}$ & $\begin{array}{c}\text { Flexural } \\
\text { strength/ } \\
\mathrm{MPa}\end{array}$ & $\begin{array}{c}\text { Compres } \\
\text { sive } \\
\text { strength/ } \\
\mathrm{MPa}\end{array}$ & $\begin{array}{c}\text { Average } \\
\text { Flexural } \\
\text { strength/ } \\
\mathrm{MPa}\end{array}$ & $\begin{array}{c}\text { Average } \\
\text { Compres } \\
\text { sive } \\
\text { strength/ } \\
\mathrm{MPa}\end{array}$ \\
\hline \multirow{5}{*}{$5-1-1$} & $\mathrm{a}$ & 3.4 & 10.15 & & \\
& $\mathrm{~b}$ & 3.1 & 9.7 & 3.2 & 9.65 \\
& $\mathrm{c}$ & 3.1 & 9.1 & & \\
\cline { 2 - 6 } $5-1-2$ & $\mathrm{a}$ & 3.3 & 15.25 & & \\
& $\mathrm{~b}$ & 2.7 & 16.3 & 2.87 & 15.93 \\
& $\mathrm{c}$ & 2.6 & 16.25 & & \\
\cline { 2 - 6 } $5-1-3$ & $\mathrm{a}$ & 2.2 & 13.05 & & \\
& $\mathrm{~b}$ & 2.7 & 15 & 2.47 & 14 \\
& $\mathrm{c}$ & 2.5 & 13.95 & & \\
\hline
\end{tabular}

Parameter setting: the pressure of the gas was about $0.2 \mathrm{MPa}$. The initial carbonization temperature was about $15^{\circ} \mathrm{C}$, which risen to $22^{\circ} \mathrm{C}$ during the process of carbonization. However, compared with $28^{\circ} \mathrm{C}$, which was the initial environment temperature of carbonization, the rise of temperature is not obvious, indicating that the carbonization reaction is slow. Therefore, the environment temperature of carbonization should avoid being too low.

During the process of this experiment, the low-temperature showed no obvious change. Compared with the temperature change when the initial carbonization temperature was $28^{\circ} \mathrm{C}$ and the result of the mechanical experiment of the specimen, 
too-low temperature was against the carbonization reaction of the specimen, nor the growth of the strength of which. The entire chemical activity of the material tended to decrease, even carbonization itself is an exothermic reaction, it can barely offset the decrease of chemical activity and the reaction rate caused by too-low environment. And the fact that the temperature did not significantly increase could be viewed as its macroscopic display. Compressive and lexural strength are shown in Figure 2:

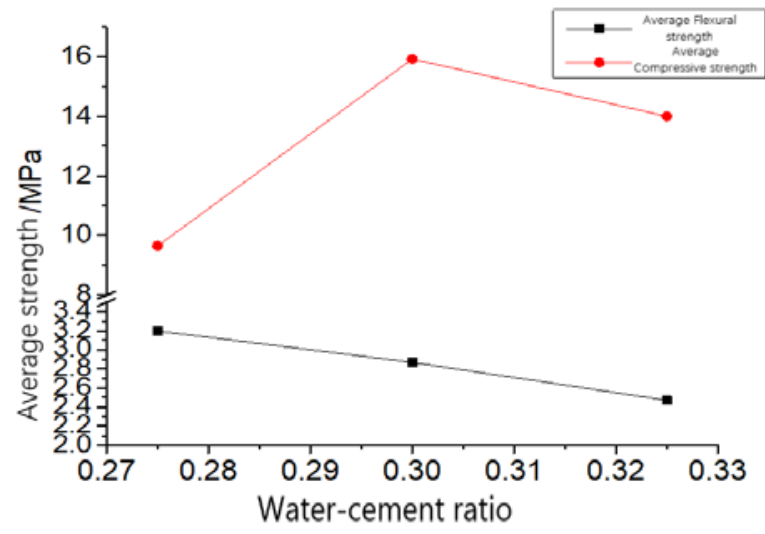

Figure 2. Comparison chart of the strength of gas carbonization experiment on magnesium slag under pressurized atmosphere with different water-cement ratio

Compared with the result of atmospheric pressure, it can be seen that the compressive and flexural strength of the specimen follow no obvious rule under the conditions of three water-cement ratios. The flexural strength gradually decreased with the increase of the water-cement ratio, while the compressive strength had an increased trend in general with a sudden change at the water-cement ratio of 0.3 .

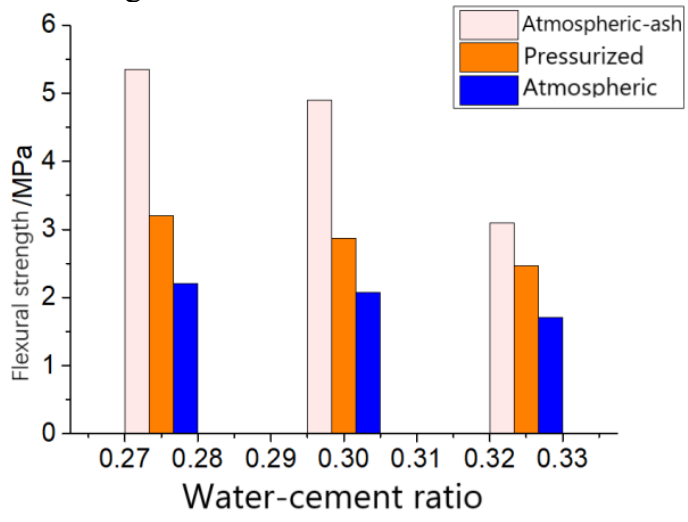

(a) Comparison chart of the flexural strength

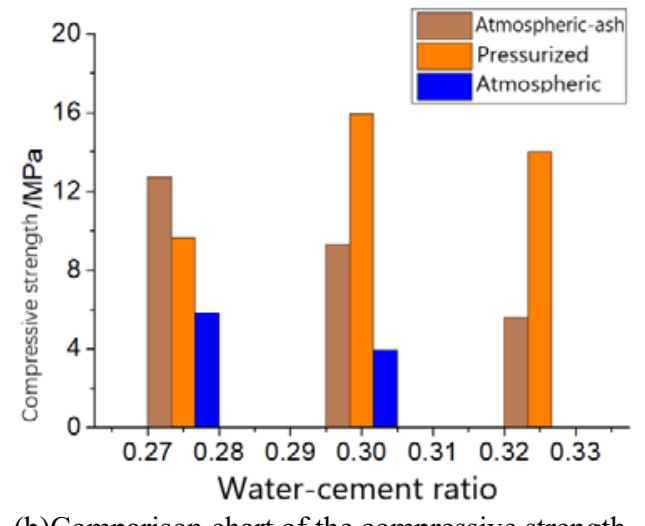

(b)Comparison chart of the compressive strength

Figure3. Comparison charts of mechanical property of gas carbonization experiment on magnesium slag in gas under

atmospheric pressure and pressurized atmosphere

From Figure 3, it can be seen that the mechanical property results of the two experiments under atmospheric pressure with same water-cement ratio are quite different, it can be concluded that there is a certain error. However, the mechanical properties are relatively stable under pressurized atmosphere, and from the results of the compression experiment, carbonization under pressurized atmosphere is obviously better than that of the two carbonization under atmospheric pressure in results. In order to make a more intuitive comparison, the results of the two carbonization experiments under atmospheric pressure have been averaged as shown in the following charts. As the Figure4 illustrated, the results show that the experiment under pressurized atmosphere can better enhance the strength.

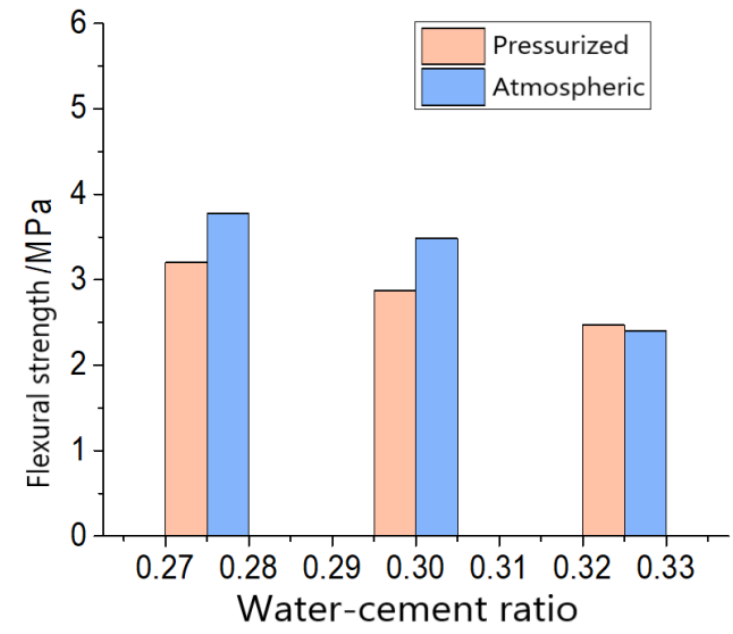




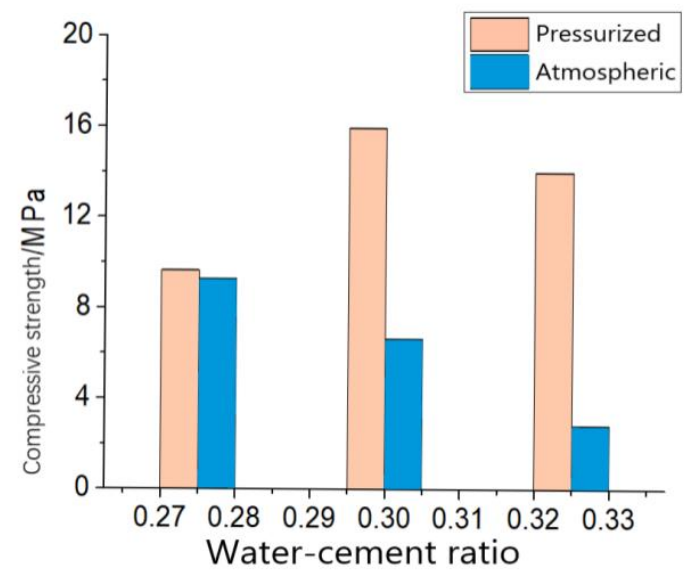

Figure4. Comparison charts of average strength of gas carbonization experiment on magnesium slag in gas under atmospheric pressure and pressurized atmosphere

\section{Conclusion}

Compared with the uncarbonized experimental group, the strength of pure magnesium slag was enhanced by carbonization under atmospheric pressure, but the compressive strength was not proportional to the increase of the flexural strength, which means there is still room for improvement. The specimen carbonized under pressure can not fully react, and the strength of such specimen cannot be enhanced to the maximum extent.

The result of the gas carbonization experiment under pressurized atmosphere shows that the carbonization curing under pressurized atmosphere has a certain enhancement in strength compared with carbonization curing under atmospheric pressure, indicating that the strength of the specimen is related to the degree of carbonization. The more fully carbonized the specimen is, the more obvious the strength enhances, showing that carbonization is feasible for the strength enhancement of magnesium slag.

\section{Acknowledgments}

Thank my mentor, Professor Ma, for his guidance in academic research, which makes me full of interest and motivation in research. Professor Ma's attitude towards scientific research has always influenced me. At the same time, I would like to thank my brother Chen Guo for his great help in establishing the finite element model, conceiving the whole article and processing the data.

\section{Reference}

1. Xiao Lg, Wang Sy, Luo F. Research and Prospect Analysis of Application Status of Industrial Waste
Residues Such as Magnesium Slag [J]. Journal of Jilin Jianzhu University, 2008, 25(1): 1-7.

2. Li Zh, Cui Zzh. Experimental Study on Carbonation Characteristics of C30 Magnesium Slag Concrete $[\mathrm{J}]$. Concrete and Cement Products, 2015(4): 86-89.

3. Zhang Xx, Zhao Yy, Liang Qf. Road Use Research of Industrial Waste Magnesium Slag [J]. Road Construction, 1997(2): 35-40.

4. Zhang X. Effect of Medium on $\gamma-\mathrm{C} 2 \mathrm{~S}$ Hydration [J]. Journal of Building Materials, 1989(4): 323-328.

5. Liwu Mo, Yuanyuan Hao, Yunpeng Liu, et al. Preparation of calcium carbonate binders via $\mathrm{CO}$ 2 activation of magnesium slag. 2019, 121:81-90. 